\title{
A Fatal Case of Triple Whammy in an Elderly Patient
}

Pietro Gareri ${ }^{1,2}$, Giovanni Ruotolo ${ }^{3}$, Alberto Castagna ${ }^{1}$, Valeria Graziella Laura Manfredi ${ }^{4}$, Alfonso Merante ${ }^{3}$, Norma Maria Marigliano ${ }^{5}$, Andrea Corsonello ${ }^{6}$, Luca Gallelli ${ }^{*}$, Amalia Cecilia Bruni ${ }^{1}$, Santo Gratteri ${ }^{7}$ and Giovambattista De Sarro ${ }^{2}$

${ }^{1}$ Centro Regionale di Neurogenetica - ASP Catanzaro, Catanzaro, Italy

${ }^{2}$ Chair of Pharmacology, Department of Health Science, School of Medicine, University "Magna Graecia” of Catanzaro, Clinical Pharmacology and Pharmacovigilance Unit, Policlinico Germaneto, Catanzaro, Italy

${ }^{3}$ Geriatric Unit, "Pugliese-Ciaccio" Hospital, Catanzaro, Italy

${ }^{4}$ Cardiothoracic Surgery Unit, University of Messina, Messina, Italy

${ }^{5}$ SERT - ASP Taranto, Taranto, Italy

${ }^{6}$ Unit of Geriatric Pharmaco epidemiology, Italian National Research Center on Aging (INRCA), Cosenza, Cosenza, Italy

${ }^{7}$ Chair of Forensic Medicine, Department of Experimental Medicine, School of Medicine, University of Catanzaro, Italy

"Corresponding author: Luca Gallelli, Chair of Pharmacology, Department of Health Science, School of Medicine, University of Catanzaro, Clinical Pharmacology and Pharmacovigilance Unit, Policlinico Germaneto, Viale Europa - Germaneto 88100 Catanzaro, Italy, Tel: +39-0961-712322; E-mail: gallelli@unicz.it

Rec date: Dec 31, 2014; Acc date: Mar 27, 2015; Pub date: Mar 30, 2015

Copyright: (c) 2015 Gareri P, et al. This is an open-access article distributed under the terms of the Creative Commons Attribution License, which permits unrestricted use, distribution, and reproduction in any medium, provided the original author and source are credited.

\begin{abstract}
Triple whammy is a drug-induced renal failure which in patients treated with ACE-inhibitors or angiotensin II receptor blockers, diuretics and non-steroidal anti-inflammatory drugs.

We report a case of a 79-year-old woman affected with hypertension, depression and arthritis that was hospitalized for abdominal pain and discharged with normal renal function and with poly-treatment: furosemide, aspirin, carvedilol, omeprazole and ramipril. Few days later she was visited for depressive symptoms, pain in the right shoulder and cystitis and treatment with oral ketoprofen and ciprofloxacin was prescribed.

One week later she experienced loss of appetite, asthenia and swelling of the face. Blood analyses showed acute renal failure, whereas clinical examination showed heart failure and pleural effusion. She was again hospitalized in a geriatric ward for metabolic acidosis. Drug treatments and hemodialysis did not improve clinical conditions and she died thirteen days after her hospitalization.

History suggested the onset of drug-related acute renal failure probably due to the combination of furosemide, ketoprofen and ramipril, defined as triple whammy.
\end{abstract}

Keywords: Acute renal failure; Diuretic; ACE-inhibitor; NSAID; Drug-interaction

\section{Introduction}

Adverse drug reactions (ADRs) represent a common problem during drug treatment $[1,2]$ and may induce organ failure, particularly in the elderly $[3,4]$.

In the elderly, poly-treatment is common in patients with heart failure and hypertension [5] and these drugs may induce the development of pharmacokinetic as well as pharmacodynamic drugdrug interactions $[6,7]$.

Moreover, elderly patients may have chronic inflammatory diseases or chronic non cancer pain, so a treatment with a non-steroidal antiinflammatory drug (NSAID) might be indicated [8-11].

The combination ofan angiotensin converting enzyme-inhibitor (ACEI) or an angiotensin II receptor blocker (ARB), a diuretic and a NSAID may increase the risk of acute kidney injury, calledtriple whammy, because each drug is able to affect kidney function through different mechanisms [12,13].In particular, diuretics can lead to hypovolaemia, ACE-inhibitors/ARBs cause haemodynamic decrease of glomerular filtration rate due to efferent arteriolar vasodilation, and NSAIDs inhibit prostacyclin synthesis (thus leading to renal afferent arteriolar vasoconstriction) [14-16].

In this paper we report a case of fatal acute kidney injury in an elderly poly-treated woman.

\section{Case Report}

A 79-year-old woman with history of hypertension, depression and arthritis was hospitalized for abdominal pain and discharged with normal renal function(serum creatinine $=0.82 \mathrm{mg} / \mathrm{dL}$, normal values 0.7-1.2 mg/dL; Chronic Kidney Disease Epidemiology Collaboration: $84.1 \mathrm{~mL} / \mathrm{min}$, normal values $>60 \mathrm{~mL} / \mathrm{min}$ ) and with the following pharmacological treatment: furosemide $(25 \mathrm{mg} /$ day $)$, aspirin $(100 \mathrm{mg} /$ day), carvedilol (12.5 mg/day), omeprazole $(20 \mathrm{mg}$ /day) and ramipril ( $5 \mathrm{mg} /$ day). Few days later she was visited at home for the worsening of depressive symptoms, pain in the right shoulder and cystitis and treatment with oral ketoprofen (160 mg/day) and ciprofloxacin (250 mg bid) was prescribed.

About one week later she experienced loss of appetite, asthenia and swelling of the face, therefore she was hospitalized. Clinical examination showed heart failure and pleural effusion while blood 
chemical analyses showed acute renal failure (creatinine $5.6 \mathrm{mg} / \mathrm{dL}$ ) and metabolic acidosis ( $\mathrm{pH}=6.1$, normal values: $7.35-7.45 ; \mathrm{PaCO} 2=39$ mmHg, normal values: $35-45 ; \mathrm{HCO}=18 \mathrm{mEq} / \mathrm{L}$, normal range: 22-26). Bicarbonate administration and hemodialysis did not improve the clinical conditions and the patient died thirteen days later.

\section{Discussion}

We described a case of drug-related acute renal failure, defined as triple whammy, in an elderly woman, related to drug drug-interaction induced by inappropriate prescription.

Inappropriate prescription is the use of drugs with risks greater than the possible benefits, inappropriate dosing duration, prescriptions that lead to clinically significant drug-drug and drugdisease interactions, and the underuse of potentially beneficial medications [17-19].

In particular, inappropriate prescription seems to be common in the elderly with a prevalence of $40 \%-50 \%$ among nursing home residents [20], and 19\%-28\% among community dwelling patients $[21,22]$.

In our case report, the patient was treated with ramipril (ACEinhibitor) and furosemide (diuretic) for hypertension with a good control of symptoms and without the development of renal failure.

Recently, Lapi et al. [13] documented an overall increased risk of acute kidney injury with a triple therapy combination but not with a double therapy combination in a retrospective study evaluating 487.372 patients. In fact, during the treatment with diuretics and NSAIDs (without an ACEI or an ARB), despite a reduction in renal blood flow (caused by diuretics) and the presence of renal afferent arteriolar constriction, glomerular filtration is probably maintained as a result of the effect of angiotensin II mediated efferent arteriolar vasoconstriction and sodium retention [23-25]. On the other hand, among patients taking ACEIs or ARBs and NSAIDs (without a diuretic), the afferentvaso constrictive stimulus induced by the NSAIDs through the inhibition of prostacyclin synthesis is probably insufficient to substantially increase the risk of acute kidney injury in the presence of a normal extracellular fluid volume and preserved renal blood flow.

In our case report, the development of pain induced a new clinical evaluation and a prescription of ketoprofen (NSAID). NSAIDs are very dangerous and potentially harmful when co-administered with ACEIs or diuretics; in fact, the patient developed fatal acute renal failure about one week after the NSAID administration.

The mechanisms of renal failure could be related to an early and severe deteriorating effect of the NSAID in our patient, concomitantly treated with ACEI and furosemide; as above reported it is also dependent on the blockade of prostacyclin synthesis, which play a crucial role for maintaining renal function. In fact, acute renal failure or acute kidney injury can occur in patients with underlying volume depletion or ineffective blood volume, in those with preexisting renal insufficiency, and of course, in the elderly [26].

A cross-sectional study involving patients admitted to a teaching hospital general medical ward has specifically documented an increased risk of acute kidney injury associated with the concomitant use of diuretics, ACE inhibitors and NSAIDs [12].

However, must be remembering that at home the patient received a treatment with ciprofloxacin and we can't exclude a role of ciprofloxacin in the severe worsening of symptoms. In fact several papers have documented an association between ciprofloxacin and nephrotoxicity $[27,28]$, therefore in our patient ciprofloxacin treatment may have played a role in the fatal impairment of clinical conditions.

Furthermore, it is conceivable that this serious impairment of clinical function has induced a cardiorenal syndrome, with the development of severe heart failure responsible for the death.

Take together these data, we think that drug-drug interaction induced a clinical impairment that, precipitated by ciprofloxacin administration, induced a severe cardio renal syndrome with severe severe heart failure and death.

However, we have not able to demonstrate this because we have not data of heart function at the time of clinical impairment (before the exacerbation: ejection fraction $68 \%$ ).

\section{Conclusions}

In conclusion, our case report shows that doctors may take attention during the treatment of elderly patients. An accurate pharmacological analysis needs to be always performed before the prescription of a new drug, in order to avoid the development of potentially fatal drug interactions. Finally, we must emphasize the need for increased clinical monitoring of poly-treated patients, in order to perform an early recognition and treatment of adverse reactions.

\section{References}

1. Giofrè C, Scicchitano F, Palleria C, Mazzitello C, Ciriaco M, et al. (2013) Pharmacovigilance and drug safety in Calabria (Italy): 2012 adverse events analysis. J Pharmacol Pharmacother 4: S55-60.

2. Scicchitano F, Giofre C, Palleria C, Mazzitello C, Ciriaco M, et al. (2012) Pharmacovigilance and drug safety 2011 in Calabria (Italy): Adverse events analysis. Journal of research in medical sciences: the official journal of Isfahan University of Medical Sciences 17: 872-875.

3. Sino CG, Bouvy ML, Jansen PA, Schop IM, Egberts TC, et al. (2013) Signs and symptoms indicative of potential adverse drug reactions in homecare patients. J Am Med Dir Assoc 14: 920-925.

4. Gallelli L, Ferreri G, Colosimo M, Pirritano D, Guadagnino L, et al. (2002) Adverse drug reactions to antibiotics observed in two pulmonology divisions of catanzaro, Italy: a six-year retrospective study. Pharmacol Res 46: 395-400.

5. Obreli Neto PR, Nobili A, Marusic S, Pilger D, Guidoni CM, et al. (2012) Prevalence and predictors of potential drug-drug interactions in the elderly: a cross-sectional study in the brazilian primary public health system. Journal of pharmacy \& pharmaceutical sciences : a publication of the Canadian Society for Pharmaceutical Sciences, Societe canadienne des sciences pharmaceutiques 15: 344-354.

6. Palleria C, Di Paolo A, Giofre C, Caglioti C, Leuzzi G, et al. (2013) Pharmacokinetic drug-drug interaction and their implication in clinical management. Journal of research in medical sciences 18: 601-610.

7. Rende P, Paletta L, Gallelli G, Raffaele G, Natale V, et al. (2013) Retrospective evaluation of adverse drug reactions induced by antihypertensive treatment. Journal of pharmacology \& pharmacotherapeutics 4: S47-50.

8. O'Neil CK, Hanlon JT, Marcum ZA (2012) Adverse effects of analgesics commonly used by older adults with osteoarthritis: focus on non-opioid and opioid analgesics. Am J Geriatr Pharmacother 10: 331-342.

9. McCartney CJ, Nelligan K (2014) Postoperative pain management after total knee arthroplasty in elderly patients: treatment options. Drugs Aging 31: 83-91. 
Citation: Gareri P, Ruotolo G, Castagna A, Manfredi VGL, Merante A, et al. (2015) A Fatal Case of Triple Whammy in an Elderly Patient. J

Page 3 of 3

10. Gallelli L, Galasso O, Falcone D, Southworth S, Greco M, et al. (2013) The effects of nonsteroidal anti-inflammatory drugs on clinical outcomes, synovial fluid cytokine concentration and signal transduction pathways in knee osteoarthritis. A randomized open label trial. Osteoarthritis and cartilage / OARS, Osteoarthritis Research Society 21: 1400-1408.

11. Gallelli L, Galasso O, Urzino A, Saccà S, Falcone D, et al. (2012) Characteristics and clinical implications of the pharmacokinetic profile of ibuprofen in patients with knee osteoarthritis. Clin Drug Investig 32: 827-833.

12. Loboz KK, Shenfield GM (2005) Drug combinations and impaired renal function -- the 'triple whammy'. Br J Clin Pharmacol 59: 239-243.

13. Lapi F, Azoulay L, Yin H, Nessim SJ, Suissa S (2013) Concurrent use of diuretics, angiotensin converting enzyme inhibitors, and angiotensin receptor blockers with non-steroidal anti-inflammatory drugs and risk of acute kidney injury: nested case-control study. BMJ 346: e8525.

14. Bentley ML, Corwin HL, Dasta J (2010) Drug-induced acute kidney injury in the critically ill adult: recognition and prevention strategies. Crit Care Med 38: S169-174.

15. Pannu N, Nadim MK (2008) An overview of drug-induced acute kidney injury. Crit Care Med 36: S216-223.

16. Schetz M, Dasta J, Goldstein S, Golper T (2005) Drug-induced acute kidney injury. Curr Opin Crit Care 11: 555-565.

17. Spinewine A, Schmader KE, Barber N, Hughes C, Lapane KL, et al. (2007) Appropriate prescribing in elderly people: how well can it be measured and optimised? Lancet 370: 173-184.

18. Al Aqqad SM, Chen LL, Shafie AA, Hassali MA, Tangiisuran B (2014) The use of potentially inappropriate medications and changes in quality of life among older nursing home residents. Clin Interv Aging 9: 201-207.
19. Gareri P, Gallelli L, Lacava R, Castagna A, Corsonello A et al. (2014) Iatrogenic Delirium in an Elderly Patient: When Drugs are Harmful. J Gerontol Geriat Res 3:140.

20. Aparasu RR, Mort JR (2000) Inappropriate prescribing for the elderly: beers criteria-based review. Ann Pharmacother 34: 338-346.

21. Fialova D, Topinkova E, Gambassi G, Finne-Soveri H, Jonsson PV et al. (2007) Potentially inappropriate medication use among home care elderly patients in Europe. Pharm World Sci 29: 444-444.

22. Fialová D1, Topinková E, Gambassi G, Finne-Soveri H, Jónsson PV, et al. (2005) Potentially inappropriate medication use among elderly home care patients in Europe. JAMA 293: 1348-1358.

23. Schetz M, Dasta J, Goldstein S, Golper T (2005) Drug-induced acute kidney injury. Curr Opin Crit Care 11: 555-565.

24. Greger R (2000) Physiology of renal sodium transport. Am J Med Sci 319: 51-62.

25. Taber SS, Pasko DA (2008) The epidemiology of drug-induced disorders: the kidney. Expert Opin Drug Saf 7: 679-690.

26. Kane-Gill SL, Sileanu FE, Murugan R, Trietley GS, Handler SM et al. (2014) Risk Factors for Acute Kidney Injury in Older Adults with Critical Illness: A Retrospective Cohort Study. American journal of kidney diseases.

27. Khan M, Ortega LM, Bagwan N, Nayer A (2015) Crystal-induced acute kidney injury due to ciprofloxacin. J Nephropathol 4: 29-31.

28. Qian Q, Nasr SH, Akogyeram CO, Sethi S (2012) Myoglobin-associated acute kidney injury in the setting of ciprofloxacin administration. American journal of kidney diseases 59: 462-466. 